\title{
A SUBSIDIARIEDADE COMO PRINCÍPIO DENSIFICADOR DA EFETIVAÇÃO DOS DIREITOS SOCIAIS PRESTACIONAIS NO ESTADO FEDERAL BRASILEIRO: 0 CASO DO MUNICÍPIO DE PELOTAS/RS
}

Subsidiarity as a principle that enhances the establishment of social rights in the Brazilian Federal State: the case of the Municipality of Pelotas/RS

${ }^{1}$ Universidade Federal de Pelotas. Faculdade de Direito. Pelotas/RS, Brasil. Correspondência: uassam@gmail.com

Recebido: 15/08/2019. Revisado: 29/01/2020. Nova revisão: 04/06/2020. Aprovado: $17 / 2020$ 


\section{RESUMO}

Este artigo teve como objetivo analisar a relação federativa entre a União e o município em face da prestação do direito social à saúde. As dimensões do pacto federativo analisadas foram a competência administrativa e a competência de arrecadar diretamente recursos financeiros. A partir dessas duas competências, pôde-se identificar a existência (ou não) do equilíbrio entre o ente central e o ente periférico. O estudo pautou-se pelo princípio da subsidiariedade, pois tal princípio refere-se à distribuição de competências. A pesquisa empregou o método hipotético-dedutivo, com pesquisa bibliográfica, considerando as hipóteses de distribuição de competências e de receitas financeiras conjuntamente com os gastos públicos com a saúde, para analisar se o ente municipal possuía autonomia suficiente para realizar suas obrigações constitucionais relativas à saúde.

\section{Palavras-Chave}

Direito à Saúde; Efetivação; Federalismo; Solidariedade; Subsidiariedade.

\section{ABSTRACT}

The objective of this article was to analyze the federative relationship between the Union and Municipality in the face of the provision of the social right to health. The dimensions of the federative pact analyzed were the administrative competence and the competence to directly raise financial resources. From these two competences, it was possible to identify the existence (or not) of the balance between the central the peripheral entities. The study was based on the principle of subsidiarity, as this principle refers to the distribution of competences. The research applied the hypothetical-deductive method, with bibliographic research, considering the hypotheses of distribution of competences and financial income together with public spending on health, in order to analyze whether the municipal entity had sufficient autonomy to fulfill its constitutional obligations related to health.

\section{Keywords}

Right to health; Effectiveness; Federalism; Solidarity; Subsidiarity. 


\section{Introdução}

O objetivo deste artigo foi analisar se a relação entre a distribuição federativa de competências administrativa e financeira contribui para a efetividade da prestação ao direito à saúde no Estado brasileiro. Tendo como base a concepção de Estado federal, o estudo partiu de três pressupostos: (i) o princípio da subsidiariedade é aplicável, devido a seu aspecto organizacional de competências (administrativa e financeira); (ii) a efetividade de um direito prestacional não reside apenas na existência ou ausência de recursos financeiros, mas em como e por quem esses recursos são geridos ${ }^{1}$; (iii) as modificações, ao longo da vigência da Constituição Federal de $1988(\mathrm{CF} / 88)^{2}$, que convergiram recursos financeiros ao poder central (União) ao retirar "poder financeiro" dos entes periféricos (municípios), enfraquecendo-os economicamente, como mostra Arretche ${ }^{3}$. Esses pressupostos serviram como delimitadores da análise, pois a temática pode ser estudada por outros ângulos e elementos. Optou-se pela distribuição federativa das competências administrativas e financeiras para demonstrar um ponto de fragilidade no pacto federativo.

Ao optar pela forma federativa de Estado (art. $1^{\circ}$, caput, CF/88), o constituinte originário decidiu adotar a lógica específica da federação, estabelecendo o Estado brasileiro a partir das peculiaridades de um Estado federal. Isso inclui a existência de entes que possuem determinado grau constitucional de autonomia administrativa, política e financeira, mas que formam uma unidade, que é o soberano Estado federal. Dessa forma, está-se diante de um Estado descentralizado em relação às competências e, por conseguinte, à prestação de serviços públicos. Destaca-se que, em uma federação, as competências de cada ente federado devem ser respeitadas pelos outros, principalmente pelo ente central. Nisso incide o princípio da subsidiariedade. Em decorrência da dinâmica federativa, deve haver também o princípio da solidariedade, pois cada ente depende da cooperação - administrativa, econômica e política - do outro para que a unidade possa ser mantida no Estado.

Em tempo, este artigo não tratou da subsidiariedade entre o Estado e a sociedade civil, que, para Torres, foi acolhida na CF/88 nos seguintes artigos: 197; 198 , inciso III; 204; 205; 206, inciso IV; 216, parágrafo $1 ; 225$; e 227, parágrafo $1^{0^{4}}$. Contesta-se essa visão, pois o que esses artigos indicam é a solidariedade, e não a espécie de solidariedade, ou seja, a subsidiariedade. Isso pelo fato de o texto constitucional não atribuir precedência de competência em todos dispositivos para a sociedade civil; tais artigos constitucionais indicam que tanto o Estado como a

\footnotetext{
${ }^{1}$ BARBOSA, Jeferson Ferreira. Direito à saúde e solidariedade na Constituição brasileira. Porto Alegre: Livraria do Advogado, 2014. p. 68.

2BRASIL. Constituição da República Federativa do Brasil de 1988. Disponível em: http://www.planalto.gov. br/ccivil_03/constituicao/constituicaocompilado.htm. Acesso em: 02 jul. 2021.

${ }^{3}$ ARRETCHE, Marta. Democracia, federalismo e centralização no Brasil. Rio de Janeiro: FGV; Fiocruz, 2012.

${ }^{4}$ TORRES, Silvia Faber. O princípio da subsidiariedade no direito público contemporâneo. Rio de Janeiro: Renovar, 2001. p. 148.
} 
sociedade civil atuarão em conjunto, e não que a sociedade civil atuará isoladamente e, quando houver dificuldade para satisfazer os objetivos constitucionais, o Estado a auxiliará. Ainda, alguns desses dispositivos atribuem a competência ao Estado e, ao mesmo tempo, abrem a possibilidade de a sociedade civil contribuir/agir. Assim, os artigos que de fato carregam o princípio da subsidiariedade são: 197, in fine, e 204, inciso I, da CF/ $/ 88^{5}$.

Outra dimensão analisada neste artigo foi a prestação do direito social à saúde, efetuada estritamente vinculada à dinâmica das relações estabelecidas entre o ente central (União) ${ }^{6}$ e o ente periférico (município). Estima-se que a população brasileira seja de 213.451.417 pessoas, todas residindo em ao menos um município (zonas urbana e rural) - daí a importância do município na federação. Ao elencar diversos direitos sociais, a CF/88 estabeleceu a relação entre a forma e a substância do Estado, ou seja, entre o Estado federal e o social. Destarte, para que a forma possa estar adequada à substância, a organização de competências administrativa e financeira deve ser a mais adequada possível para a efetivação da prestação do direito à saúde. Optou-se pela análise do direito à saúde em razão da complexidade do sistema e da competência administrativa comum entre os entes federados.

Com o objetivo de fazer a análise de um exemplo concreto, o estudo centrou-se nos aspectos administrativos e financeiros da relação entre a União e o Município de Pelotas (RS). Salienta-se que não foram esgotadas todas as possibilidades de análise, mas que se buscou destacar a disfuncionalidade financeira da relação federativa existente entre União e municípios. Por consequência, em alguns momentos apareceu o ente mediano (Estado-membro do Rio Grande do Sul), embora não seja o foco do estudo. A escolha de Pelotas deu-se pelo fato de o autor deste artigo residir no município e pela suposta facilidade de conseguir dados técnicos. Também se salienta que esse município tem porte médio, com área territorial de $1.610,084 \mathrm{~km}^{2}$ e população de 343.132 pessoas, segundo estimativa de $2021^{7}$, sendo um exemplo que abarca municípios de estrutura administrativa mediana que recebem demandas de saúde de outros municípios com menor capacidade de as absorver.

\section{Metodologia}

Utilizou-se o método-hipotético dedutivo, que permite que um problema seja identificado e, depois, que as soluções levantadas sejam testadas. A questão

\footnotetext{
${ }^{5}$ SOUZA, Paulo Fernando Mohn e. A subsidiariedade como princípio de organização do Estado e sua aplicação no federalismo. Brasília: Senado Federal, Subsecretaria de Edições Técnicas, 2010. p. 47-48.

${ }^{6}$ INSTITUTO BRASILEIRO DE GEOGRAFIA E PESQUISA - IBGE. Estimativas da população residente para os municípios e para as unidades da federação. ftp://ftp.ibge.gov.br/Estimativas_de_Populacao/ Estimativas_2018/estimativa_dou_2018_20181019.pdf. Acesso em: 11 ago. 2021.

${ }^{7}$ INSTITUTO BRASILEIRO DE GEOGRAFIA E PESQUISA - IBGE. Panorama Pelotas. https://cidades.ibge.gov.br/ brasil/rs/pelotas/panorama. Acesso em: 11 ago. 2021.
} 
central tratada por esta pesquisa foi a efetividade da prestação à saúde a partir das competências administrativa e financeira no contexto do administrativo-financeiro do Estado federal brasileiro. Para tanto, aplicaram-se os pressupostos acima indicados, que delimitaram a análise do objeto de estudo, ao mesmo tempo em que indicaram como esse direito tem sido concretizado, em termos gerais, por meio do viés administrativo-financeiro.

Por conseguinte, analisaram-se dados do Município de Pelotas, quais sejam, o Projeto de Lei Orçamentária de $2018^{8}$, a Lei Complementar n. 141/2012 ${ }^{9}$, a Lei Orgânica do Município ${ }^{10}$ e da Secretaria Municipal de Saúde, especificamente o que tange à transferência de recursos do Sistema Único de Saúde (SUS), a fim de obter uma projeção de se as indicações previamente estabelecidas estavam adequadas, fático e normativamente, ao sistema federativo brasileiro no que se refere à relação entre arrecadação e prestação do direito à saúde. Para tal, suscintamente, fez-se um levantamento de fontes de arrecadação financeira de competência dos municípios e da União e das respectivas obrigações relativas à saúde. Com isso, foi possível estabelecer, perspectivamente, o ponto de desequilíbrio na relação entre arrecadação financeira e obrigações relativas à saúde. Logo, buscou-se demonstrar a disfuncionalidade organizacional na forma federativa do Estado no que tange à concretização do direito à saúde.

\section{Estado federal social}

A designação de Estado federal social exprime, normativamente, a forma adotada pelo Estado brasileiro a partir do texto constitucional de 1988. Para esta análise, destaca-se o Estado brasileiro em suas formas federada e social. A primeira está explicitada nos artigos $1^{\circ}$, caput, 18 e $60, \$ 4^{\circ}, \mathrm{I}$, da CF/88. Já a forma social encontra-se implícita na no preâmbulo da CF/88 e nos artigos $1^{\circ}$, inciso IV, $3^{\circ}, 6^{\circ}$ e 170, incisos III e VII - ao contrário, e.g., do texto constitucional alemão de 1949 (art. 28, Abs. 1).

Assim, se o texto constitucional exprime normas (princípios e regras) explícitas e implícitas, então as formas federal e social do Estado brasileiro vinculam o

\footnotetext{
${ }^{8}$ MUNICÍPIO DE PELOTAS. Lei n. 6539, de 05 de janeiro de 2018. Disponível em: https://leismunicipais. com.br/a/rs/p/pelotas/lei-ordinaria/2018/654/6539/lei-ordinaria-n-6539-2018-estima-a-receita-e-fixa-adespesa-do-municipio-para-o-exercicio-financeiro-de-2018. Acesso em: 02 jul. 2021.

${ }^{9}$ BRASIL. Lei Complementar n. 141, de 13 de janeiro de 2012. Regulamenta o $\S 3^{\circ}$ do art. 198 da Constituição Federal para dispor sobre os valores mínimos a serem aplicados anualmente pela União, Estados, Distrito Federal e Municípios em ações e serviços públicos de saúde; estabelece os critérios de rateio dos recursos de transferências para a saúde e as normas de fiscalização, avaliação e controle das despesas com saúde nas 3 (três) esferas de governo; revoga dispositivos das Leis nos 8.080, de 19 de setembro de 1990, e 8.689, de 27 de julho de 1993; e dá outras providências. Disponível em: http://www.planalto.gov.br/ccivil_03/leis/ Icp/Icp141.htm. Acesso em: 02 jul. 2021.

${ }^{10}$ MUNICÍPIO DE PELOTAS. Lei Orgânica do Município de Pelotas/RS. Disponível em: https://leismunicipais. com.br/lei-organica-pelotas-rs. Acesso em: 02 jul. 2021.
} 
ordenamento jurídico e, por conseguinte, os poderes do Estado em todos os seus níveis. Se assim se constitui o Estado constitucional brasileiro, não se pode separar a forma federativa da dimensão social do Estado. Será constitucional toda lei, ação administrativa e decisão judicial que estiver de acordo com a forma federativa e social. Dependendo do caso concreto, a federação será o fundamento ou Estado social ou, ainda, tanto a federação e o Estado social. Tanto a federação quanto o aspecto social, dessa forma, passam a ser parâmetros normativos objetivos ${ }^{11}$, a serem critérios de escolha da política de efetivação de direitos, especificamente, aqui, os fundamentais sociais.

\section{Forma federativa}

A forma federativa compreende um Estado federal soberano composto de entes estatais autônomos, vertical e horizontalmente ${ }^{12}$ associados e institucionalizados. Os entes federativos devem gozar de autodeterminação (auto-organização, autogoverno, autolegislação e autofinanciamento) dentro da esfera de competência arquitetada politicamente ${ }^{13}$ pela $\mathrm{CF} / 88^{14}$, sem estarem subordinados hierarquicamente ao poder central, mas organizados de forma a cooperarem com ele ${ }^{15}$. Este é o caso explícito da competência comum que envolve o direito à saúde (Lei n. 8.080/19900 ${ }^{16}$, que trata do Sistema Único de Saúde - SUS).

O Estado federal é marcado pela descentralização - distribuição de funções entre diferentes entes governamentais ${ }^{17}$-, redundando na repartição de competências, que é essencial ao federalismo e que deve ser um dos fatores de eficiência de governo e instrumento de limitação do poder. Os níveis de poder existentes devem ter suas atribuições de competências delimitadas a fim de coexistirem e atuarem simultânea e harmonicamente, mantendo a diversidade e o pluralismo de interesses da sociedade civil ${ }^{18}$. Com isso, reduz-se o risco de desequilíbrio e conflito entre os

\footnotetext{
${ }^{11}$ ENDERS, Christoph. Sozialstaatlichkeit im Spannungsfeld von Eigenverantwortung und Fürsorge. In: VERÖFFENTLICHUNGEN der Vereinigung der Deutschen Staatsrechtslehrer. 64. Berlin: De Gruyter Rechtswissenschaften, 2005. p. 13-14.

${ }^{12}$ SARLET, Ingo Wolfgang, MARINONI, Luiz Guilherme, MITIDIERO, Daniel. Curso de direito constitucional. 3. ed. São Paulo: Revista dos Tribunais, 2014. p. 774

${ }^{13}$ SOUZA, Paulo Fernando Mohn e. op. cit., p. 72.

${ }^{14}$ ALMEIDA, Fernanda Dias Menezes de. Competências na constituição de 1988. 3 ed. São Paulo: Atlas, 2005. p. 26

${ }^{15}$ BARBOSA, Jeferson Ferreira. op. cit., p. 17-30; ALMEIDA, Fernanda Dias Menezes de. op. cit., p. 25, 29; TORRES, Silvia Faber. op. cit., p. 215-216, 220-221, 229-230. Não se adentrará na polêmica de enfraquecimento do federalismo a partir da adoção do federalismo cooperativo que, em tese, favoreceria o ente mais forte.

${ }^{16}$ BRASIL. Lei n. 8.080, de 19 de setembro de 1990. Dispõe sobre as condições para a promoção, proteção e recuperação da saúde, a organização e o funcionamento dos serviços correspondentes e dá outras providências. Disponível em: http://www.planalto.gov.br/ccivil_03/leis//8080.htm. Acesso em: 02 jul. 2021.

${ }^{17}$ BARBOSA, Jeferson Ferreira. op. cit., p. 20.

${ }^{18}$ TORRES, Silvia Faber. op. cit., p. 211-212; SOUZA, Paulo Fernando Mohn e. op. cit., p. 213.
} 
entes federados ${ }^{19}$. A federação brasileira tem, peculiarmente, a União, os estados, os municípios e o Distrito Federal ${ }^{20}$ como entes federados.

Se há a repartição de competências, é imprescindível a repartição de recursos financeiros, que capacitam os entes federados a ser autônomos e a cumprir suas obrigações constitucionais e institucionais. Por conseguinte, deve existir o equilíbrio de encargos e arrecadação entre União, estados, Distrito Federal e municípios; se houver desequilíbrio entre receitas e encargos, o federalismo pode restar desnaturado devido à redução ou anulação da autonomia dos entes federados ${ }^{21}$.

As competências dos entes federados dividem-se em legislativa (art. 22 União; art. 30, I - municípios; e art. 25 - estados, da CF/88) e administrativa (art. 21 - União; art. 30 - municípios; e art. 25 - estados, da CF/88) ${ }^{22}$. Este estudo dá atenção à competência administrativa (material, geral ou de execução) no que concerne à prestação do direito à saúde, que é seu cerne, pois se trata de competência material comum $^{23,24}$ (art. 23, II, CF/88) por ser socialmente relevante ${ }^{25}$.

O sentido da competência administrativa de prestação à saúde é a cooperação/solidariedade entre os entes federados na execução de tarefas e objetivos estabelecidos normativamente. Em termos operacionais, a Lei n. 8.080/1990 discrimina o que é competência de cada ente federado ${ }^{26}$. Nessa distribuição de competências entre os entes, existe a preferência de atuação do ente periférico (município) em relação ao mediano (estado) e ao central (União). Isso ocorre justamente pelo fato de o artigo 30, inciso VII, da CF/88 estabelecer que cabe ao município prestar serviço de saúde à população, com a cooperação técnica e financeira da União e dos estados. Aqui, será tratada a incidência do princípio da subsidiariedade no acesso ao direito à saúde, que será visto adiante.

\section{Forma social}

O Estado social, além da manutenção da segurança (função clássica do Estado), deve proporcionar um patamar mínimo de assistência social. Ao Estado não cabe somente o (auto)controle, mas a ação social, que ocorrerá por meio da atividade da administração pública. Por conseguinte, a organização dos poderes Legislativo

\footnotetext{
${ }^{19}$ ALMEIDA, Fernanda Dias Menezes de. op. cit., p. 29-30.

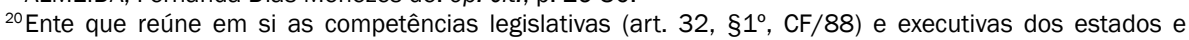
municípios. ALMEIDA, Fernanda Dias Menezes de. op. cit., p. 75.

${ }^{21}$ Id. Ibid., p. 30.

${ }^{22}$ OLIVEIRA, Regis Fernandes de. Curso de direito financeiro. 4. ed. São Paulo: Revista dos Tribunais, 2011. p. 45.

${ }^{23}$ ALMEIDA, Fernanda Dias Menezes de. op. cit., p. 130-131.

${ }^{24}$ SUPREMO TRIBUNAL FEDERAL - STF. Agravo Regimental no Recurso Extraordinário 607381. Relator: Ministro Luiz Fux. Julgamento: 31/05/2011. Publicação: 17/06/2011. Disponível em: https:// jurisprudencia.stf.jus.br/pages/search/sjur193824/false. Acesso em: 02 jul. 2021.

${ }^{25}$ ALMEIDA, Fernanda Dias Menezes de. op. cit., p. 83.

${ }^{26}$ TORRES, Silvia Faber. op. cit., p. 213.
} 
e Executivo toma outra proporção em relação a sua forma e a sua manifestação no Estado liberal. Nesse sentido, o Estado capacita-se a regular a sociedade e o mercado, bem como a estruturar a ordem social, planejando o sistema social e econômico ${ }^{27}$. Dentre as consequências dessa forma de Estado, têm-se o combate ao desemprego e o estabelecimento de serviços públicos para atender as necessidades mínimas dos indivíduos em várias áreas que tangem, diretamente, à dignidade humana (art. $1^{\circ}$, III, CF/88), como educação, saúde e moradia, dentre outras.

Portanto, existe uma dilatação das competências político-administrativa e legislativa do Estado. A organização do Estado altera-se na medida em que assume maior encargo e responsabilidade para com seus jurisdicionados, tornando-se mais complexa. Desta feita, a distribuição de encargos deve equivaler à distribuição de receita financeira entre os entes federados a partir da complexidade de suas competências e autonomias.

\section{Princípios da solidariedade e da subsidiariedade}

Este tópico trata da delimitação da solidariedade e da subsidiariedade para se ter a noção de como esses dois princípios incidem na forma federativa do Estado, cuja essência é a mútua cooperação e responsabilidade ${ }^{28}$ entre os entes federados. No caso do Estado brasileiro, têm-se a União, os estados, os municípios e o Distrito Federal. Dessa forma, na medida em que existem diferentes graus e esferas de competência - em escala de descentralização ${ }^{29}$ - entre os entes federados, torna-se necessário distinguir quando há a aplicação de um ou outro princípio.

\section{Princípio da solidariedade}

O princípio da solidariedade é exigência da natureza humana ${ }^{30}, \mathrm{o}$ zoon politikon $^{31}$, ou seja, diversas individualidades com seus interesses coexistindo em um mesmo mundo. Ele carrega em si o equilíbrio social contido na perspectiva da justiça social $^{32}$ que, de alguma forma, encontra-se implícita no Estado social e se manifesta nos direitos sociais. Consequentemente, tal princípio vincula o Estado, a sociedade e os indivíduos a atuarem em prol do todo. No caso em análise, a solidariedade incide entre os entes da federação, que são autônomos, mas que se encontram unidos e voltados a um objetivo comum, formando um Estado federal soberano. Aqui, a ideia de soberania é empregada no sentido clássico, com o objetivo de assentar a ideia de integração de diversos entes federados em um único Estado.

\footnotetext{
${ }^{27}$ TORRES, Silvia Faber. op. cit., p. 52.

${ }^{28}$ /d. Ibid., p. 88.

${ }^{29}$ PONTES DE MIRANDA, Francisco Cavalcanti. Comentários à Constituição de 1946. 3. ed. Rio de Janeiro: Borsoi, 1960. t. 1, p. 229.

${ }^{30}$ TORRES, Silvia Faber. op. cit., p. 90.

${ }^{31}$ ARISTÓTELES. Politik. Übers. Franz Susemihl. 3. Aufl. Hamburg: Rowohlts, 2009. p. $46-47$ (1253a).

${ }^{32}$ PIAZOLO, Michael. Solidarität. Deutungen zu einem Leitprinzip der Europäischen Union. Würzburg; Ergon, 2004. p. 81.
} 


\subsection{Definição}

O princípio da solidariedade consiste na exigência de cooperação ${ }^{33}$ entre os entes federados no sentido de concretizar o bem comum e os objetivos constitucionais do Estado brasileiro, atendendo, na medida do possível, aos interesses de cada ente. A cooperação de cada ente pode se dar na forma de ação ou/e omissão; no primeiro caso, o ente federado atua em prol de um ou mais entes federados; no segundo, o ente federado omite-se a fim de beneficiar ou não prejudicar um ou mais entes federados. Por conseguinte, a solidariedade é compreendida a partir das circunstâncias fáticas nas quais se encontra o ente federado. É estabelecida uma relação de contribuição/ajuda mútua entre os entes, em nível quer vertical, quer horizontal de competências.

\subsection{Incidência na Federação}

A solidariedade tem como fim manter a coesão da unidade do Estado federal, estabelecendo a igualdade - inclusive material - entre seus entes e entre os indivíduos submetidos à jurisdição da União (art. 19, III, CF/88, e.g. os objetivos constitucionais de garantir o desenvolvimento nacional e reduzir as desigualdades regionais no art. $3^{\circ}$, II e III, in fine, CF/88). A solidariedade não é um princípio que estabelece mecanismos de atribuições de competência entre os entes federados, como é o princípio subsidiariedade. A solidariedade condiz com a ação dos entes federados em prol do bem de um ou de todos, ou seja, o bem comum. Ela pode ocorrer - excepcionalmente - em face da competência privativa ou - normalmente - da competência comum.

O princípio da solidariedade tem caráter geral em relação ao da subsidiariedade, pelo fato de o dever de solidariedade ser gênero em relação à espécie - a subsidiariedade ${ }^{34}$ garante uma ação conjunta entre o ente periférico e o ente central na medida em que o primeiro tenha dificuldades em realizar suas obrigações, levando ou não em conta a competência do periférico. A subsidiariedade deve necessariamente levar em consideração a competência do ente periférico. Um exemplo constitucional de solidariedade é o caso de calamidades públicas (art. 21, XVIII, CF/88).

\section{Princípio da subsidiariedade}

O princípio da subsidiariedade projeta a defesa de esfera autônoma dos entes periféricos em face da intervenção injustificada do ente central. Se, por um lado, ele prima pela não intervenção na autonomia dos entes periféricos (ou inferiores), por outro defende o auxílio do ente central (ou superior) perante as necessidades dos entes periféricos, direcionado ao bem comum. Por isso, trata-se de princípio

\footnotetext{
${ }^{33}$ ZOLL, Rainer. Was ist Solidarität heute? Frankfurt am Main: Suhrkamp, 2000. p. 13.

${ }^{34}$ PIAZOLO, Michael. op. cit., p. 82-83.
} 
que prima pela diversidade e pelo pluralismo em vários domínios - político, social, econômico, jurídico - entre os entes periféricos (municípios) e o central (União), respeitando os diferentes centros de decisão política ${ }^{35}$.

A concepção moderna do princípio de solidariedade situa-se entre o final do século XIX e o início do XX, contrapondo-se às ideologias socialistas em favor da autonomia e do pluralismo social, mas também contrariando o liberalismo clássico, defensor do distanciamento do Estado no âmbito social. Por conseguinte, o princípio da subsidiariedade refere-se, acentuadamente, à relação com o indivíduo, à coletividade $\mathrm{e}$ ao Estado $^{36}$. Embora se possa desenvolver essa perspectiva em face do direito ao acesso à saúde, o presente texto trabalha com o princípio da subsidiariedade projetado no sistema federativo, que, da mesma forma, relaciona os entes periféricos (municípios), medianos (estados e Distrito Federal) e central (União).

\subsection{Definição}

O princípio da subsidiariedade, por ser aplicado em vários domínios da cultura humana e preservar a diversidade e o pluralismo, deve apresentar um conceito baseado na relação que, a partir de sua noção, é estabelecida entre os elementos em interação. Dessa forma, o princípio da subsidiariedade orienta um sistema de distribuição de competências entre o ente central e o ente periférico, de forma que a instância mais próxima ao cidadão tenha prevalência de competência em relação à que é mais distante, sendo que estas devem intervir em auxílio e favorecimento da eficácia e da necessidade da primeira ${ }^{37}$.

Portanto, existe a obrigação de não ingerência (dimensão negativa) do ente central (União) sobre o ente periférico (município ou estado) quando este garantir, por si só e de forma eficaz, a realização de seu próprio interesse. Porém, quando o ente periférico não tiver condições de satisfazer eficazmente seus interesses, suas necessidades e suas carências, o ente central deve auxiliá-lo (dimensão positiva). Nessa razão, o ente central é subsidiário ao ente periférico, somente agindo - impelido pelo bem comum - quando o periférico não puder atuar de forma eficiente ${ }^{38}$.

\subsection{Incidência na Federação}

A subsidiariedade é um princípio implícito em nosso ordenamento constitucional $^{39}$ decorrente da organização federativa do Estado, a qual pressupõe a

\footnotetext{
${ }^{35}$ TORRES, Silvia Faber. op. cit., p. 7-9, 16-17; SOUZA, Paulo Fernando Mohn e. op. cit., p. 69.

${ }^{36}$ TORRES, Silvia Faber. op. cit., p. 7. Não se defende um Estado subsidiário, por isso, também, que o texto analisará a aplicação do princípio da subsidiariedade no estado Federal e não entre o Estado e o indivíduo.

${ }^{37}$ Id. Ibid., p. 34.

${ }^{38}$ Id. Ibid., p. 9-10, 12, 18.

${ }^{39} / d$. Ibid., p. 242.
} 
solidariedade entre os entes federados, que são política, administrativa e financeiramente autônomos entre si. Dessa forma, a subsidiariedade é empregada como princípio de estrutura e gradação da repartição de competências entre as esferas da federação (União, estados, municípios e Distrito Federal) ${ }^{40}$. Também incluída como regra de solução de conflito de atribuições que surja entre os entes federa$\operatorname{dos}^{41}$, sendo que o poder local deve manter prerrogativas de gestão administrativa por estar (mais) próximo do cidadão ${ }^{42}$.

Destaca-se que a subsidiariedade revela a necessidade de se encontrar um equilíbrio entre a ingerência e a não ingerência econômica, administrativa e social do ente central no ente periférico. Outrossim, a função da subsidiariedade é de assistência (em sentido amplo) do ente central ao periférico, suprindo a insuficiência financeira, logística, administrativa ou outra quando o ente periférico não puder efetivamente realizar suas obrigações a partir dos limites de sua competência ${ }^{43}$. Destaca-se o aspecto financeiro quando se trabalha com políticas públicas nacionais, mas de efetivação conforme as características e as necessidades locais. Nesse caso, o governo local deve assumir maior protagonismo, desde que sua efetivação, estrutura político-administrativo e econômica se coadunem com a do todo federativo ${ }^{44}$.

Por isso, as diretivas gerais - e.g. de políticas públicas - são elaboradas no âmbito da União, e as específicas - próprias da atuação - são de competência dos entes periféricos. Nesse talante, o princípio da subsidiariedade desdobra-se juridicamente no sentido da suplementariedade - que se refere à conservação da repartição entre duas dimensões de atribuições a órgãos que se distinguem uns dos outros a partir das relações existentes entre si - e em complementariedade - que diferencia as exigências resultantes de compromissos de distintas atribuições de diferentes órgãos da administração pública dos entes federados ${ }^{45}$.

\section{Efetivação da prestação do direito social à saúde}

Os direitos fundamentais de segunda dimensão constituem-se em direitos econômicos, sociais e culturais (e.g. art. $\left.6^{\circ}, \mathrm{CF} / 88\right)$. Em relação a esses direitos, o Estado assume a postura ativa, em determinados casos, no sentido prestacional $^{46}$;

\footnotetext{
${ }^{40}$ TORRES, Silvia Faber. op. cit., p. 97.

${ }^{41}$ SUPREMO TRIBUNAL FEDERAL - STF. Recurso Extraordinário 730721/SP - São Paulo. Relator: Ministro Edson Fachin. Julgamento: 02/10/2015. Publicação: 07/10/2015. Disponível em: https://jurisprudencia. stf.jus.br/pages/search/despacho571035/false. Acesso em: 02 jul. 2021.

${ }^{42}$ TORRES, Silvia Faber. op. cit., p. 35-36.

${ }^{43}$ Id. Ibid., p. 19-20.

${ }^{44}$ BARACHO, José Alfredo de Oliveira. O princípio de subsidiariedade: conceito e evolução. Revista da Faculdade de Direito da Universidade Federal de Minas Gerais, Belo Horizonte, n. 35. p. 13-14; 17-18 e 28-29, 1995. Disponível em: https://revista.direito.ufmg.br/index.php/revista/article/view/1470/1399.

${ }^{45}$ Id. Ibid., p. 32-33.

${ }^{46}$ SARLET, Ingo Wolfgang. A eficácia dos direitos fundamentais: uma teoria geral dos direitos fundamentais na perspectiva constitucional. 13. ed. Porto Alegre: Livraria do Advogado, 2018. p. 191-214.
} 
ele promove a satisfação de pretensões dos cidadãos ${ }^{47}$. As questões que surgem são: quais pretensões e de quem devem ser satisfeitas pelo Estado e em qual nível (total ou parcial)? Em relação às respostas a estes questionamentos, o Estado (poder público) terá um dever de se organizar de forma que efetive os direitos sociais de maneira administrativamente eficiente. Vale destacar que essas questões não são objeto deste artigo, mas demonstram que, independentemente do nível de efetivação das pretensões dos cidadãos pelo Estado, cabe a este executá-las da melhor forma. Nesse caso, deságua-se no tema deste artigo, que é a efetivação dos direitos sociais prestacionais no Estado federal. Destarte, deve-se situar a problemática: qual ente federado deve realizar conduta obrigatória para a efetivação do resultado estabelecido na norma ${ }^{48}$ ?

Tais direitos sociais são exigíveis pelo grau de densidade da norma constitucional, ou seja, mesmo tendo baixa densidade normativa, são exigíveis se as condições fático-jurídicas assim o demandarem. Dessa forma, tem-se, em determinado grau, a geração de direito subjetivo. Destaca-se, com isso, que nas normas de cunho programático - sem a devida interpositio legislatoris - é possível, por vezes, deduzir um direito subjetivo individual ${ }^{49}$. Parte-se dessa concepção pelo fato de se atribuir às normas constitucionais o mínimo de força normativa, pois, se dependesse do legislador infraconstitucional regulamentar um dispositivo constitucional a fim de que gere efetivos jurídicos, a soberania da Constituição no ordenamento jurídico estaria na discricionariedade do legislador infraconstitucional, e não na própria Carta Magna.

Partindo-se do mínimo de exigibilidade dos direitos fundamentais sociais prestacionais, tem-se que o Estado (os entes federados em sua dimensão administrativa) necessita dos meios para efetivá-los. A efetivação depende da organização constitucional das competências dos entes federados. A organização do Estado brasileiro (art. $1^{\circ}$, caput; c/c art. 18, caput, CF/88) faz com que a atuação estatal na efetivação dos direitos sociais prestacionais seja dividida solidariamente entre os entes federados.

O direito fundamental à saúde está estritamente vinculado à vida e à garantia de uma existência digna (art. $1^{\circ}$, III, CF/88; c/c art. $2^{\circ}$, caput, Lei n. 8.080/1990) ${ }^{50}$. Ressalta-se que o próprio texto constitucional tratou de estabelecer as linhas gerais de como o direito à saúde seria estruturado pela administração pública, com o auxílio da iniciativa privada (arts. 196 a 200, CF/88). Pode-se identificar que as prestações que envolvem o direito à saúde são diversas (art. $6^{\circ}$, Lei n. 8.080/1990), envolvendo fiscalização, gestão, assistência, controle, proteção, participação, formulação e incremento

\footnotetext{
${ }^{47}$ SCHÄFER, Jairo. Classificação dos direitos fundamentais: do sistema geracional ao sistema unitário. 3. ed. Porto Alegre: Livraria do Advogado, 2018. p. 55-56.

${ }^{48}$ Id. Ibid., p. 79.

${ }^{49}$ SARLET, Ingo Wolfgang. op. cit., p. 307-308.

${ }^{50}$ Id. Ibid., p. 317, 319.
} 
de várias atividades direta e indiretamente relacionadas ao campo da saúde. Trata-se de um sistema complexo que é um meio para efetivar o fim (o direito à saúde). Por isso, o "custo" das prestações materiais vinculadas à saúde é alto, dependendo incontornavelmente da equivalente alocação de recursos ${ }^{51}$.

\section{Subsidiariedade e efetividade do acesso à saúde}

$\mathrm{O}$ direito à saúde encontra-se situado na esfera de competência material comum: a União, os estados e os municípios (e o Distrito Federal) compartilham a responsabilidade em relação ao direito à saúde (art. 23, II, c/c art. 30, VII, CF/88; art. 198, I, CF/88; arts. $4^{\circ}$ e 7º, XI, Lei n. 8.080/1990). Ainda, em termos de demanda judicial, os três entes federados possuem responsabilidade solidária conforme entendimento do Supremo Tribunal Federal (STF) ${ }^{52}$. Destaca-se que o artigo 30, inciso VII, da CF/88, além de densificar o artigo 23, inciso $\mathrm{II}^{53}$, estabelece as relações de solidariedade e de subsidiariedade. A solidariedade encontra-se na obrigação de cooperação técnica e financeira dos entes federados para com o município, já a subsidiariedade incide na obrigação do ente periférico de prestar serviços de atendimento de saúde à população. As competências administrativas municipais relativas à saúde (art. 30, VII, CF/88) consistem nas atribuições comuns (art. 15, Lei n. 8.080/1990) realizadas por todos os entes federados - e as privativas (art. 18, Lei n. 8.080/1990) - realizadas somente pelo ente municipal. O princípio da solidariedade incide no caso das competências comuns, em que pese se possa admitir a preferência de um dos entes federados na realização de uma ação. No referente às competências privativas, incidirá, quando necessário, o princípio da subsidiariedade, estabelecendo a precedência do ente periférico na criação e manutenção das condições para o acesso à saúde. Cabe ao ente central garantir, como suplência, a realização efetiva de tal acesso $^{54}$. Destaca-se que a obrigação prestacional, conforme a redação do artigo 30, inciso VII, da CF/88, recai sobre o município. Trata-se da competência - "quase exclusiva" - de prestar o acesso ao serviço de saúde. Corrobora-se essa perspectiva com artigo 198 da CF/88 $58^{5}$ e o artigo 15, caput, do Decreto n. 7.508/2011 ${ }^{56}$, que regulamenta a Lei. n. 8.080/1990, ao estabelecer que o planejamento da saúde terá sentido ascendente, ou seja, do ente local ao nacional ${ }^{57}$.

\footnotetext{
${ }^{51}$ SARLET, Ingo Wolfgang. Direitos fundamentais em espécie. In: SARLET, Ingo Wolfgang, MARINONI, Luiz Guilherme, MITIDIERO, Daniel. Curso de direito constitucional. 3. ed. São Paulo: Revista dos Tribunais, 2014. p. 576.

52SARLET, Ingo Wolfgang, MARINONI, Luiz Guilherme, MITIDIERO, Daniel. op. cit., p. 598.

${ }^{53}$ BARBOSA, Jeferson Ferreira. op. cit., p. 33.

${ }^{54}$ TORRES, Silvia Faber. op. cit., p. 99.

${ }^{55}$ BARBOSA, Jeferson Ferreira. op. cit., p. 36.

${ }^{56}$ BRASIL. Decreto n. 7.508, de 28 de junho de 2011. Regulamenta a Lei $n^{\circ} 8.080$, de 19 de setembro de 1990, para dispor sobre a organização do Sistema Único de Saúde - SUS, o planejamento da saúde, a assistência à saúde e a articulação interfederativa, e dá outras providências. Disponível em: http://www. planalto.gov.br/ccivil_03/_ato2011-2014/2011/decreto/d7508.htm. Acesso em: 02 jul. 2021.

${ }^{57}$ BARBOSA, Jeferson Ferreira. op. cit., p. 37.
} 
Contudo, é preciso delinear a competência administrativa concernente à legislação infraconstitucional relacionada ao SUS, que faz o movimento de destacar o ente periférico por meio do processo de descentralização. Isso se dá, também, pela participação da comunidade na gestão do SUS, pela divisão de competências administrativas e pelas transferências intergovernamentais de recursos financeiros relativos à saúde ${ }^{58}$.

Nota-se que o esforço do texto da CF/88 no sentido de descentralização de poder é acompanhado pelas ideias de subsídio, assistência e auxílio. As atribuições dos estados e municípios concentram a prestação de serviços públicos, sendo que a União tem compromisso subsidiário para com os demais entes da federação ${ }^{59}$. Isso se traduz em uma arquitetura em que a autoridade central não deve assumir as competências que possam ser satisfeitas pelas autoridades próximas à população.

Dessa forma, o artigo 198, inciso I, da CF/88 prevê que:

As ações e serviços públicos de saúde integram uma rede regionalizada e hierarquizada e constituem um sistema único, organizado de acordo com as seguintes diretrizes: I - descentralização, com direção única em cada esfera de governo;

Neste texto legal, as palavras que remetem à solidariedade e à subsidiariedade são: "rede", "regionalizada", "hierarquizada", "descentralização" e "direção única em cada esfera de governo" ${ }^{60}$.

Desta feita, é possível elencar argumentos em prol da autodeterminação do município: (i) está mais próximo dos cidadãos locais, conhecendo suas necessidades e carências (racionalidade administrativa) ${ }^{61}$; (ii) possui maior capacidade de tomar decisões efetivas e que impactem de forma eficaz, individual e coletivamente, em termos locais (eficiência administrativa); (iii) suas ações tendem a ser - comparativamente - mais rápidas e precisas do que as emanadas do ente central; (iv) possibilita maior participação democrática, já que o fortalecimento do poder local tem como consequência maior participação, fiscalização e controle das decisões políticas ${ }^{62}$; (v) encontra-se espacialmente delimitado em um território de pequena extensão em comparação ao território nacional, facilitando a atuação do agente público (dependendo do caso concreto). Em suma, o ente municipal tem melhores condições de definir políticas públicas de saúde, pois tem a "melhor" noção do que a população local carece e necessita. Também é ele que consegue definir os locais estratégicos onde devem estar situados hospitais, Unidades de Ponto Atendimento (UPAs), postos de

\footnotetext{
${ }^{58}$ TORRES, Silvia Faber. op. cit., p. 247.

${ }^{59}$ HORTA, Raul Machado. Federalismo e o princípio da subsidiariedade. Revista do Instituto dos Advogados de Minas Gerais, Belo Horizonte, v. 10, p. 162-163, 2002.

${ }^{60}$ GIUFFRÈ, Felice. La solidarietà nell'ordinamento costituzionale. Milano: Giuffrè, 2002. p. 149.

${ }^{61}$ SOUZA, Paulo Fernando Mohn e. op. cit., p. 70.

${ }^{62}$ TORRES, Silvia Faber. op. cit., p. 226, 238-239.
} 
saúde e pontos de vacinação, estabelecer a logística do Serviço de Atendimento Móvel de Urgência (SAMU) e outras estruturas que servem à efetivação do direito à saúde.

\section{0 exemplo do Município de Pelotas/RS no federalismo administrativo- financeiro}

Os munícipios brasileiros, por serem entes federativos, encontram-se inseridos na dinâmica do federalismo financeiro, justamente para atenderem a partilha substantiva de competências. Dessa forma, é imperativo garantir proporcionalmente os recursos financeiros necessários ao atendimento dos custos de suas competências, como determina o artigo 30, inciso VII, da CF/88. A distribuição de competências materiais é concretizável na medida em que existam recursos financeiros suficientes para mover a máquina pública. Isso os torna autônomos em relação ao ente central ${ }^{63}$.

A CF/88 estabeleceu um processo de descentralização fiscal ao fortalecer as autonomias regionais e locais, além de instituir critérios distributivos ${ }^{64}$. Contudo, ao longo das últimas décadas, ocorreu a prevalência de recursos financeiros no ente central. A União, por meio de reformas na $\mathrm{CF} / 88$, conseguiu reverter para si o sentido dos recursos financeiros. Restou assim desequilibrada, no que condiz com a seara da saúde, a previsão do sistema fiscal constitucional de fontes diretas de captação de recursos financeiros ${ }^{65}$. Por conseguinte, se a característica do federalismo é a autonomia dos entes federados, não se pode admitir a concentração de poderes no ente central.

As alterações constitucionais no federalismo financeiro levaram a União a concentrar a arrecadação financeira e transferir intergovernamentalmente os recursos aos entes federados. Um exemplo é o Fundo Social de Emergência (FSE) (Emenda Constitucional de Revisão n. 1), que retirou parcela de recursos financeiros dos entes regionais e municipais a fim de favorecer a arrecadação da União. Ele foi rebatizado, após algumas prorrogações, de Desvinculação de Receitas da União (DRU). Cabe, ainda, destacar uma série de fundos criados pela União (art. 71, Lei n. $4.320 / 1964)^{66,67,68}$.

Dessa forma, o que se pode concluir é que os entes regionais e periféricos tiveram sua autonomia financeira reduzida - e, por conseguinte, as demais autonomias -, pois precisam contar com o repasse de recursos da União. Não se está

\footnotetext{
${ }^{63}$ TORRES, Silvia Faber. op. cit., p. 254.

${ }^{64}$ Id. Ibid., p. 255.

${ }^{65}$ Id. Ibid., p. 254.

${ }^{66}$ OLIVEIRA, Regis Fernandes de. op. cit., p. 330.

${ }^{67}$ TORRES, Silvia Faber. op. cit., p. 256.

${ }^{68}$ DRU começou fundo social de emergência. Senado Notícias, 08 fev. 2000. Disponível em: https://www12. senado.leg.br/noticias/materias/2000/02/09/dru-comecou-como-fundo-social-de-emergencia. Acesso em: 13 jan. 2019.
} 
afirmando nem presumindo que a União não cumpra seu compromisso de repassar recursos financeiros, mas que as receitas financeiras não são diretas, dependendo do repasse de outro ente federado. Isso, por si só, reduz a autonomia dos entes federados. Para enfraquecer ainda mais os poderes dos entes federados, o artigo 160 , parágrafo único, da $\mathrm{CF} / 88$, prevê o condicionamento de repasses ao pagamento dos créditos da União. De fato, os entes federados no federalismo brasileiro ficam subordinados à União e dependentes dela ${ }^{69}$. Os princípios do federalismo e da subsidiariedade indicam, em termos lógicos, que o movimento deveria ser o contrário, ou seja, em direção ao fortalecimento da competência arrecadatória dos estado e municípios. O impacto é o descompasso entre as competências político-administrativa e financeira ${ }^{70}$.

Desta forma, cabe destacar as competências condizentes à União e ao município decorrentes da Lei n. 8.080/1990. No que condiz à competência comum referente à União ${ }^{71}$, estados e municípios, $\mathrm{o}$ artigo 15 possui 21 incisos que apresentam em torno de 31 atividades administrativas. Já o artigo 16 elenca as competências próprias da União, com 19 incisos e um parágrafo único que apresentam por volta de 43 atividades administrativas. $\mathrm{O}$ artigo 18 traz a relação das competências exclusivas do ente municipal, com aproximadamente 28 atividades administrativas dispostas em 12 incisos. Salienta-se que as atividades administrativas aqui apresentam diversos graus de complexidade, exigindo intensidades distintas de esforços do aparelho do Estado. O objetivo é mostrar, de forma aproximada, o grau de encargos que possuem a União e os municípios. Giza-se, fortemente, que tais números não representam maior ou menor responsabilidade de um ente em relação ao outro. Eles servem, somente, de parâmetro para se avaliar a distribuição de recursos financeiros para investimento na área da saúde no sistema federal brasileiro. Nota-se que a União acumula 74 atividades administrativas e os municípios, 59, ou seja, 15 a menos em relação ao ente central. Dessa forma, o princípio da subsidiariedade não norteou o legislador infraconstitucional, pois o ente central concentra aproximadamente $79 \%$ de competências administrativas em relação ao ente periférico.

As receitas tributárias e não tributárias diretas do Município de Pelotas são oriundas da dívida ativa; do Imposto sobre a Propriedade Predial e Territorial Urbana (IPTU) (art. 156, I, CF/88); do Imposto Sobre Serviço de qualquer natureza (ISS) (art. 156, III, CF/88); do imposto sobre "a transmissão 'intervivos', a qualquer título por ato oneroso, de bens imóveis, por natureza ou acessão física, e de direitos reais sobre imóveis, exceto os de garantia, bem como cessão de direitos a sua aquisição" (ITBI) (art. 156, II, CF/88); do Imposto sobre Propriedade Territorial Rural (ITR), de

\footnotetext{
${ }^{69}$ OLIVEIRA, Regis Fernandes de. op. cit., p. 46, 339. 0 artigo 35 da Lei n. 8.080/1990 estabelece os critérios técnicos que balizam os valores transferidos aos demais entes federados pela União.

${ }^{70}$ TORRES, Silvia Faber. op. cit., p. 255-256, 257.

${ }^{71} \mathrm{~A}$ União é responsável pela população indígena (art. 19-C), podendo os Estados-membros e Municípios atuarem complementarmente no custeio (art. 19-E) da Lei n. 8.080/1990.
} 
competência da União e cujo valor arrecadado corresponde ao valor das propriedades rurais existentes no município (art. 158, II, CF/88); do Imposto de Renda (IR), de competência da União, sendo que o valor recolhido refere-se ao número de servidores públicos do município (art. 158, I, CF/88); e de taxas, exploração do patrimônio e multas de trânsito ${ }^{72}$. O Município de Pelotas possui sete fontes de receitas próprias e duas vinculadas à União (ITR e IR), mas que ingressam sem intermediários ${ }^{73}$. A arrecadação municipal ainda depende das circunstâncias de incidência do suporte fático do tributo e da característica econômica da localidade.

A União é responsável pelo ITR (art. 153, IV, CF/88); pelo imposto sobre operações de crédito, câmbio e seguro ou sobre operações relativas a títulos ou valores mobiliários (IOF) (art. 153, V, CF/88); pelo imposto sobre a importação de produtos estrangeiros (II) (art. 153, I, CF/88); pelo imposto sobre a exportação, para o exterior, de produtos nacionais ou nacionalizados (IE) (art. 153, II, CF/88); pelo Imposto sobre Produtos Industrializados (IPI) (art. 153, IV, CF/88); pelo IR (art. 153, III, CF/88); e por taxas, exploração do patrimônio, dívida ativa e multas administrativas. Assim, a União possui dez fontes de receitas próprias ${ }^{74}$. Dessa forma, $o$ ente central, além de ter mais fontes de receitas próprias, possui, sob sua jurisdição, a movimentação financeira (em termos gerais) de todo o território brasileiro. A arrecadatória do Município de Pelotas/RS são três, restringindo-se aos contribuintes que residem e circulam em seu território. Na dimensão do federalismo financeiro, o princípio da subsidiariedade também foi relegado a segundo plano, pois não se pode afirmar, mesmo no sentido proporcional, que os entes periféricos se beneficiam da divisão de competências de arrecadação direta de recursos financeiros ${ }^{75}$ em relação à divisão de competências administrativas.

\subsection{Pelotas/RS}

Pelotas possui 165 estabelecimentos de saúde da esfera administrativa pública (seis federais, dois estaduais e 55 municipais) e privada (102 no total,

\footnotetext{
${ }^{72}$ Salienta-se, ainda, a existência da receita do artigo 20 , parágrafo $1^{\circ}$, da $\mathrm{CF} / 88$, embora o Município de Pelotas não se encaixe no suporte fático. Comparativa e exemplarmente, a fonte de arrecadação direta entre a União (ente central), estados e Distrito Federal (ente mediano) inclui os seguintes tributos: ICMS (art. 155, II, CF/88), IPVA (art. 155, III, CF/88), ITCMD (art. 155, I, CF/88), taxas, exploração do patrimônio, dívida ativa e multas administrativas.

${ }^{73}$ Salienta-se que, em termos de receitas indiretas, têm-se os repasses previstos no artigo 158 (estados) e no artigo 159, inciso I, alínea a, (União), da CF/88, que não cabe aqui detalhar. Especificamente na seara da saúde, a previsão legal da cooperação financeira da União e dos estados com os municípios encontra-se nos artigos 16, XIII, e 17, III, da Lei n. 8.080/1990.

${ }^{74}$ Deve-se levar em consideração que o volume de arrecadação financeira condiz com a quantidade de contribuintes e a qualidade do fato gerador tributário - ou seja, existem fatos geradores que incidem em setores com maior movimentação financeira, como o IPI e o IOF.

${ }^{75}$ Se existe desproporção no que condiz à saúde, devem-se somar outras competências que são próprias dos municípios. Dessa forma, a disparidade aumenta na relação entre arrecadação de recursos financeiros e encargos administrativos.
} 
sendo 92 com fins lucrativos e dez sem fins lucrativos; 34 estão no âmbito do SUS); em termos de modalidade de prestação de serviço, são 93 particulares, 81 de terceiros, seis no plano próprio e 97 no SUS; no quesito número de leitos para internação em estabelecimentos de saúde, a esfera pública tem 103 e a privada, 1.081, totalizando 1.184. Os dados são de $2009^{76}$. Pelotas conta, ainda, com dois cursos de medicina, o da Universidade Federal de Pelotas (UFPel) e o da Universidade Católica de Pelotas (UCPel).

O caso do Município de Pelotas pode demonstrar, em parte, que a distribuição de competências administrativa e financeira na federação brasileira é disfuncional, constituindo um fator a ser considerado como obstáculo para a melhor efetivação - possível - do direito à saúde. Destaca-se novamente o artigo 30, inciso VII, da $\mathrm{CF} / 88$, que estabelece a obrigação dos municípios de prestar os serviços de atendimento de saúde. Trata-se da dimensão onerosa desse direito social.

Dessa forma, inicia-se pelo Projeto de Lei Orçamentária de $2018^{77}$, que previu uma estimativa de receita de $\mathrm{R} \$ 1.128 .929 .837,40$ e a estimativa de gastos que resulta no mesmo valor. Salienta-se que o orçamento destinado à área da saúde é de R\$247.896.793,26. Segundo o projeto de lei, a Prefeitura Municipal de Pelotas encontra-se adequada aos percentuais exigidos pela $\mathrm{CF} / 88$, pela Lei Complementar n. 141/2012 (15\%) e pela Lei Orgânica do Município, com o valor de $\mathrm{R} \$ 74.280 .607,69$, levando em consideração despesas sem convênio.

Giza-se que a transferência de recursos do SUS - repasse fundo a fundo consiste na previsão de $R \$ 138.200 .537,55$. Nota-se que a transferência de recursos do SUS é mais da metade do orçamento previsto para a Secretaria Municipal de Saúde. Soma-se a isso a previsão de transferência de recursos do Estado do Rio Grande do Sul para programas de saúde - repasse fundo a fundo -, que totaliza $33.079 .648,00^{78}$. Esse é o primeiro indicador de que o Município de Pelotas possui reduzida autonomia financeira, dependendo substancialmente dos repasses de recursos de outros entes federados.

A Lei Complementar n. 141/2012 regulamenta o parágrafo $3^{\circ}$ do artigo 198, da CF/88, dispondo sobre a distribuição e aplicação dos recursos na esfera da saúde (art. 30, VII, da CF). Nesse sentido, os recursos financeiros repassados pela União aos demais entes federados (art. $12, \$ \$ 2^{\circ}$ e $4^{\circ}$ ) respeitarão uma série de critérios - previamente estabelecidos e atualizados - que envolvem as características

\footnotetext{
${ }^{76}$ INSTITUTO BRASILEIRO DE GEOGRAFIA E PESQUISA - IBGE. Serviços de saúde. https://cidades.ibge.gov.br/ brasil/rs/pelotas/pesquisa/32/28163. Acesso em: 04 jan. 2019.

${ }^{77}$ Destaca-se que não se conseguiu o acesso ao texto da lei orçamentária de 2018.

${ }^{78}$ PELOTAS. Projeto de lei que estima a receita e fixa a despesa do município para o exercício financeiro de 2018. http://sapl.camarapel.rs.gov.br/sapl_documentos/materia/24971_texto_integral. Acesso em: 05 jan. 2019.
} 
e necessidades regionais e locais (art. 17). Contudo, a Portaria de Consolidação n. $6 / 2017^{79}$ estabelece que os recursos serão repassados fundo a fundo a partir de dois blocos de financiamento (art. $3^{\circ}$, I e II). O primeiro bloco trata do custeio das ações e dos serviços públicos de saúde; o segundo bloco remete-se ao investimento na rede de serviços públicos de saúde. A referida portaria disciplina a quantidade de recursos e como serão aplicados em cada área abrangida pelo SUS.

Os recursos passados fundo a fundo devem ser aplicados conforme os objetivos do repasse (art. $3^{\circ}, \$ 2^{\circ}$ ). Trata-se de recursos financeiros vinculados, $o$ que implica restringir a liberdade de aplicação de recursos dos municípios a sua realidade, sem antes manejá-los entre fundos (quando possível) e, ainda, ter o aval da União para que o repasse financeiro seja mais significativo em uma área da saúde do que em outra, conforme as peculiaridades da localidade. Por consequência, o município tem sua autonomia reduzida, já que deve recorrer ao ente central para atender circunstâncias específicas da realidade local. Isso cria dificuldades para o ente periférico cumprir suas obrigações, ferindo também o princípio da subsidiariedade na relação essencial entre encargos e recursos financeiros.

Como elemento adicional à problemática exposta, tem-se em vigência a Emenda Constitucional n. 95/2016 $6^{80}$, que instituiu um teto de gastos públicos federais para o período de 20 anos e os vinculou à inflação. A Confederação Nacional de Municípios (CNM) ${ }^{81}$ simulou a evolução dos gastos em saúde de 2016 a 2036, pressupondo a correção de gastos pela inflação e levando em consideração um crescimento anual de $2,5 \%$. A projeção tomou por base o parâmetro orçamentário estabelecido no Projeto de Lei Orçamentária Anual do ano de 2018. As projeções são as seguintes: (i) o gasto com saúde da União em 2018 foi cerca de 1,85\% do Produto Interno Bruto (PIB) e, em 2036, tende a ser 1,18\% do PIB; (ii) o gasto com saúde em relação à Receita Corrente Líquida (RCL) em 2018 foi cerca de 14,4\% e, em 2036, será em torno de 9,2\%; e (iii) a participação dos municípios nos gastos com saúde crescerá de $40 \%$ da RCL em 2018 para 51,1\% em 2036, enquanto os gastos da União cairão de cerca de $60 \%$ para $48 \%$ da RCL. Destaque-se que essa projeção toma por base o limite da inflação aplicado pelo governo federal ao orçamento e a manutenção da exigência de aplicação do mínimo legal da RCL por parte dos municípios.

\footnotetext{
${ }^{79}$ Consolidação das normas sobre o financiamento e a transferência dos recursos federais para as ações e os serviços de saúde do Sistema Único de Saúde. BRASIL. Portaria de Consolidação n. 6/2017. Consolidação das normas sobre o financiamento e a transferência dos recursos federais para as ações e os serviços de saúde do Sistema Único de Saúde. http://bvsms.saude.gov.br/bvs/saudelegis/gm/2017/ pro006_03_10_2017.html. Acesso em: 25 fev. 2019.

${ }^{80}$ BRASIL. Emenda Constitucional n. 95, de 15 de dezembro de 2016. Altera o Ato das Disposições Constitucionais Transitórias, para instituir o Novo Regime Fiscal, e dá outras providências. Disponível em: http://www.planalto.gov.br/ccivil_03/constituicao/emendas/emc/emc95.htm. Acesso em: 02 jul. 2021.

${ }^{81}$ Agradece-se ao Professor Thiago Rafagnin (Universidade Federal do Oeste da Bahia - UFOB) pelo envio da Projeção da CONFEDERAÇÃO NACIONAL DE MUNICÍPIOS. Teto do gasto e saúde pública. https://www.cnm. org.br/cms/biblioteca/Teto\%20do\%20gasto\%20e\%20saúde\%20pública.pdf. Acesso em: 03 mar. 2018.
} 


\section{Considerações finais}

Sabe-se que este objeto pode ser analisado por outros ângulos, contudo a perspectiva escolhida demonstrou um desequilíbrio na estrutura federativa no que concerne a efetivação do direito social e prestacional à saúde. Conforme o desenvolvido no texto, é possível estabelecer, mesmo que de forma inicial, uma conclusão. Constatou-se que, em termos de competência administrativa, o município tem a prerrogativa constitucional de prestar o serviço de saúde conforme o artigo 30, inciso VII, da CF/88 - o que aponta a incidência do princípio da subsidiariedade -, mas conta com a cooperação técnico-financeira da União e dos estados.

Contudo, conforme a distribuição de competências da Lei n. 8.080/1990, a União, em termos gerais, possui maior amplitude de competências administrativas e também concentra mais fontes - principalmente impostos - de arrecadação financeira. Em termos de competência arrecadatória-financeira, o ente municipal possui menor número de fontes financeiras diretas do que o ente central, dependendo da solidariedade dos entes central e mediano; contudo, proporcionalmente, possui mais encargos do que a União na área da prestação à saúde. Dessa forma, existe uma dissonância na arquitetura federalista do Estado brasileiro, pois proporcionalmente os encargos e os recursos financeiros do município em relação ao direito à saúde não estão em equilíbrio, no sentido da manutenção da autonomia financeira e administrativa.

Tal desequilíbrio financeiro e administrativo acentuou-se com as modificações constitucionais realizadas ao longo dos anos, conforme estudo realizado por Arretche $^{82}$. Desde 1988, a Constituição Federal foi sendo modificada com o intuito de concentrar recursos financeiros na União, retirando-os dos estados e Distrito Federal e dos municípios. Sendo assim, o federalismo brasileiro converge à União, forçando os entes periféricos a recorrer ao ente central para conseguirem cumprir suas obrigações constitucionais de prestações de saúde, como é o caso do Município de Pelotas, cuja estimativa de recursos à Secretaria Municipal de Saúde revela que um pouco mais da metade desses recursos depende de repasses da União e do Estado do Rio Grande do Sul. Essa dependência torna a máquina pública lenta e atávica, uma vez que os problemas locais estão vinculados a ações ou recursos que não estão, necessariamente, próximos. Isso não significa que o sistema não possa ser eficaz, mas cria uma disfuncionalidade/dificuldade, na medida em que o ente periférico se encontra estritamente dependente do ente central. Destaca-se, ainda, que se está a falar de milhares de municípios e não de um apenas. Tais entraves reduzem a autonomia de um ente federado, tornando-o dependente do ente central.

A evidência disso - e a tentativa de equalizar esse desequilíbrio - encontra-se nas decisões judiciais que solidarizam financeiramente os três entes federados no

\footnotetext{
${ }^{82}$ ARRETCHE, Marta. op. cit.
} 
que tange à prestação à saúde ${ }^{83}$, efetivando a cooperação financeira prevista no artigo 30, inciso VII, da CF/88.

Contudo, a via judicial deve ser paliativa, ou seja, cabe ao legislador reorganizar a distribuição de competências, ao menos as arrecadatórias, privilegiando os municípios a fim de lhes ofertar suporte financeiro que equivalha a suas obrigações, dando-lhes autonomia financeira. Destarte, a ideia de federação com entes autônomos vai se fortalecer, tendo o ente local o protagonismo de atender às demandas constitucionais e sociais específicas de seu território urbano e rural.

\section{Referências}

ALMEIDA, Fernanda Dias Menezes de. Competências na constituição de 1988. 3 ed. São Paulo: Atlas, 2005.

ARISTÓTELES. Politik. Übers. Franz Susemihl. 3. Aufl. Hamburg: Rowohlts, 2009.

ARRETCHE, Marta. Democracia, federalismo e centralização no Brasil. Rio de Janeiro: FGV; Fiocruz, 2012.

BARACHO, José Alfredo de Oliveira. O princípio de subsidiariedade: conceito e evolução. Revista da Faculdade de Direito da Universidade Federal de Minas Gerais, Belo Horizonte, n. 35. p. 13-52, 1995. Disponível em: https://revista.direito.ufmg.br/index.php/revista/article/ view/1470/1399.

BARBOSA, Jeferson Ferreira. Direito à saúde e solidariedade na Constituição brasileira. Porto Alegre: Livraria do Advogado, 2014.

BRASIL. Portaria de Consolidação n. 6/2017. Consolidação das normas sobre o financiamento e a transferência dos recursos federais para as ações e os serviços de saúde do Sistema Único de Saúde. http://bvsms.saude.gov.br/bvs/saudelegis/gm/2017/prc0006_03_10_2017.html. Acesso em: 25 fev. 2019.

CONFEDERAÇÃO NACIONAL DE MUNICÍPIOS. Teto do gasto e saúde pública. https:// www.cnm.org.br/cms/biblioteca/Teto\%20do\%20gasto\%20e\%20saúde\%20pública.pdf. Acesso em: 03 mar. 2018.

CONSTITUTE Project. Disponível em: https://www.constituteproject.org/?lang=en. Acesso em: 05 dez. 2018.

\footnotetext{
${ }^{83}$ RECURSO EXTRAORDINÁRIO. CONSTITUCIONAL E ADMINISTRAIVO. DIREITO À SAÚDE. TRATAMENTO MÉDICO. RESPONSABILIDADE SOLIDÁRIA DOS ENTES FEDERADOS. REPERCURSÃO GERAL RECONHECIDA. REAFIRMAÇÃO DE JURISPRUDÊNCIA. O tratamento médico adequado aos necessitados se insere no rol dos deveres do Estado, porquanto responsabilidade solidária dos entes federados. 0 polo passivo pode ser composto por qualquer um deles, isoladamente, ou conjuntamente. SUPREMO TRIBUNAL FEDERAL - STF. Recurso Extraordinário 855178 RG/SE - Sergipe. Repercussão geral no recurso extraordinário. Relator: Ministro Luiz Fux. Julgamento: 05/03/2015. Publicação: 16/03/2015. Disponível em: https://jurisprudencia.stf.jus.br/pages/search/repercussao-geral7141/false. Acesso em: 02 jul. 2021.
} 
DRU começou fundo social de emergência. Senado Notícias, 08 fev. 2000. Disponível em: https://www12.senado.leg.br/noticias/materias/2000/02/09/dru-comecou-como-fundosocial-de-emergencia. Acesso em: 13 jan. 2019.

ENDERS, Christoph. Sozialstaatlichkeit im Spannungsfeld von Eigenverantwortung und Fürsorge. In: VERÖFFENTLICHUNGEN der Vereinigung der Deutschen Staatsrechtslehrer. 64. Berlin: De Gruyter Rechtswissenschaften, 2005. p. 7-52.

GIUFFRÈ, Felice. La solidarietà nell’ordinamento costituzionale. Milano: Giuffrè, 2002.

HORTA, Raul Machado. Federalismo e o princípio da subsidiariedade. Revista do Instituto dos Advogados de Minas Gerais, Belo Horizonte, v. 10, p. 153-167, 2002.

INSTITUTO BRASILEIRO DE GEOGRAFIA E PESQUISA - IBGE. Áreas dos Municípios. https:/www.ibge.gov.br/geociencias-novoportal/organizacao-do-territorio/estruturaterritorial/15761-areas-dos-municipios.html?=\&t=sobre. Acesso em: 11 ago. 2021.

INSTITUTO BRASILEIRO DE GEOGRAFIA E PESQUISA - IBGE. Estimativas da população residente para os municípios e para as unidades da federação. $\mathrm{ftp}: / / \mathrm{ftp}$.ibge.gov.br/ Estimativas_de_Populacao/Estimativas_2018/estimativa_dou_2018_20181019.pdf. Acesso em: 11 ago. 2021.

INSTITUTO BRASILEIRO DE GEOGRAFIA E PESQUISA - IBGE. Panorama Pelotas. https://cidades.ibge.gov.br/brasil/rs/pelotas/panorama. Acesso em: 04 jan. 2019.

INSTITUTO BRASILEIRO DE GEOGRAFIA E PESQUISA - IBGE. Serviços de saúde. https://cidades.ibge.gov.br/brasil/rs/pelotas/pesquisa/32/28163. Acesso em: 04 jan. 2019.

OLIVEIRA, Regis Fernandes de. Curso de direito financeiro. 4. ed. São Paulo: Revista dos Tribunais, 2011.

PIAZOLO, Michael. Solidarität. Deutungen zu einem Leitprinzip der Europäischen Union. Würzburg; Ergon, 2004.

PONTES DE MIRANDA, Francisco Cavalcanti. Comentários à Constituição de 1946. 3. ed. Rio de Janeiro: Borsoi, 1960. t. 1.

SARLET, Ingo Wolfgang, MARINONI, Luiz Guilherme, MITIDIERO, Daniel. Curso de direito constitucional. 3. ed. São Paulo: Revista dos Tribunais, 2014.

SARLET, Ingo Wolfgang. A eficácia dos direitos fundamentais: uma teoria geral dos direitos fundamentais na perspectiva constitucional. 13. ed. Porto Alegre: Livraria do Advogado, 2018.

SARLET, Ingo Wolfgang. Direitos fundamentais em espécie. In: SARLET, Ingo Wolfgang, MARINONI, Luiz Guilherme, MITIDIERO, Daniel. Curso de direito constitucional. 3. ed. São Paulo: Revista dos Tribunais, 2014.

SCHÄFER, Jairo. Classificação dos direitos fundamentais: do sistema geracional ao sistema unitário. 3. ed. Porto Alegre: Livraria do Advogado, 2018. 
Subsidiariedade como princípio da efetivação de direitos sociais: o caso de Pelotas/RS

SOUZA, Paulo Fernando Mohn e. A subsidiariedade como princípio de organização do Estado e sua aplicação no federalismo. Brasília: Senado Federal, Subsecretaria de Edições Técnicas, 2010.

TORRES, Silvia Faber. O princípio da subsidiariedade no direito público contemporâneo. Rio de Janeiro: Renovar, 2001.

ZOLL, Rainer. Was ist Solidarität heute? Frankfurt am Main: Suhrkamp, 2000.

\section{Agradecimentos}

Agradecemos à Prefeitura e à Secretaria de Saúde do Município de Pelotas/ RS pelas informações ofertadas. Um agradecimento especial a Ana Costa, secretária municipal de Saúde de Pelotas, e a Fábio Silveira Machado, chefe de gabinete da prefeita Paula Mascarenhas.

Guilherme Camargo Massaú - Pós-doutorado pela Pontifícia Universidade Católica do Rio Grande do Sul (PUC-RS); doutorado em Direito Público pela Universidade do Vale do Rio dos Sinos (Unisinos); mestrado em Direito pela Universidade de Coimbra (Portugal). Professor da graduação e da pós-graduação na Universidade Federal de Pelotas (UFPel). Pelotas/RS, Brasil.E-mail: uassam@gmail.com 